\title{
HYDROSTATIC GENERATOR OF NON-PERIODIC PRESSURE IMPULSES FOR TESTING TECHNICAL PRODUCTS
}

\author{
Nizhegorodov A.I. ${ }^{1}$, Gavrilin A.N. ${ }^{2}$, Moyzes B.B. ${ }^{2 \star}$, Ismailov G.M. ${ }^{3}$ \\ 1 Irkutsk National Research Technical University, nastromo_irkutsk@mail.ru \\ ${ }^{2}$ National Research Tomsk Polytechnic University, Tomsk, Russia, mbb@tpu.ru \\ 3Tomsk State Pedagogical University, Tomsk, Russia, gmismailov@rambler.ru
}

\begin{abstract}
The article reviews the possibility of using the hydrostatic generators of oscillators with nonlinear power elements (elastic shells) as part of the structures of various test benches in the field of mechanical tests for vibration strength and vibration resistance, as well as when testing with external and internal pressure. The hydrostatic generator of non-periodic pressure impulses for engineering products testing is a new patented technical solution in the field of testing machines. The ratios of the angular velocities of the shafts, which provides the movement of the operating fluid into the actuator of the test bench in the form of a non-periodic function and with impulses varying in amplitude in a random manner were obtained. It makes a continuous and non-repetitive sequence of pressure impulses and corresponds to the operation of the tested objects in real conditions. The random nature of the amplitudes settings is provided by signals controlled from electric generators through controlled hydraulic valves. The development of a hydrostatic generator with a power element in the form of an elastic shell is represented by a hydromechanical diagram of a generator of non-periodic pressure impulses with corresponding kinematic and dynamic dependencies. In addition, there were developed three hydro-mechanical systems with the use of a new hydrostatic generator for engineering products testing both for mechanical random vibration and for testing the external and internal pressure of engineering objects that operate in such conditions. The result of the research is the expansion of the range of systems and methods for the test processes implementation under random non-periodic force effects on various engineering objects.
\end{abstract}

Keywords: hydrostatic generator, non-periodic pressure impulses, technical products, testing.

\section{Introduction}

The vibration damage on mechanisms, hydraulic and pneumatic devices, electronic and radio relay devices, on-board computers and other mechanical and electrical devices is due to the resonance phenomena. The dynamic loads arising in this case lead to functions disorder and mechanical breakdowns of structural elements of such devices: wire breakage, leakage, short circuits, electrical contacts breakdown, breakdown of various frames, racks, brackets, etc. [1-3]. About 70\% of failures of such and similar products in mechanical engineering are the results of vibration [3-10]. The use of hydrostatic generator of oscillators with nonlinear power elements (elastic shells) in the structure of testing and a number of technological machines makes it possible to implement a variety of controlled processes. Such dynamic systems are used, for example, in technological processes of vibration transportation and vibration segregation of bulk materials [1], in the systems for dynamic damping of harmful vibrations [2]. They are very promising in the field of engineering products testing for vibration strength and vibration resistance [11-13].

At present, many technical instruments and devices are being developed for various underwater technical objects, which require testing of a large number of instruments and apparatus at high external pressure with variable pulses [14-19]. This is a new application of the developed hydro-mechanical systems for mechanical effect testing, as well as external and internal variable pressure impulses [20,21].

The purpose of the research is to synthesize a hydrostatic generator with a power element in the form of an elastic shell to create non-periodic pressure impulses for different type's machines testing.

\section{Hydrostatic generator of non-periodic pressure impulses}

To create non-periodic pressure pulses, there are power section and a control system in the hydrostatic generator (Fig. 1). The basis of the power section is an elastic shell 1 (high pressure hydraulic hose), clamped between the plates of the plungers 2 and screw pairs 3 , and fixed in the generator housing. On one side (top), a connection fitting is inserted into it, by which the generator is connected to the hydraulic line of the 
operating mechanism, and on the other (below) - a high-pressure valve 4 with a conical shut-off element, which, if necessary, provides a hermetic shut-off of the hydraulic line of the regulated pump 5. When the valve 4 is open, a given volume of operating fluid is pumped through the shell per unit time. The pump valve 5 provides adjustment of the pressure in the shell and the hydraulic system of the actuator.

Eccentrics 6 with equal eccentricities are located between the pairs of plungers. Rolling bearings 7 are placed on the surfaces of the eccentricities. With the "neutral" position of the eccentrics (see the left and right pairs of plungers), there is a minimum clearance between the ends of the plungers and the bearings, which excludes simultaneous contact of the eccentric with two plungers at once.

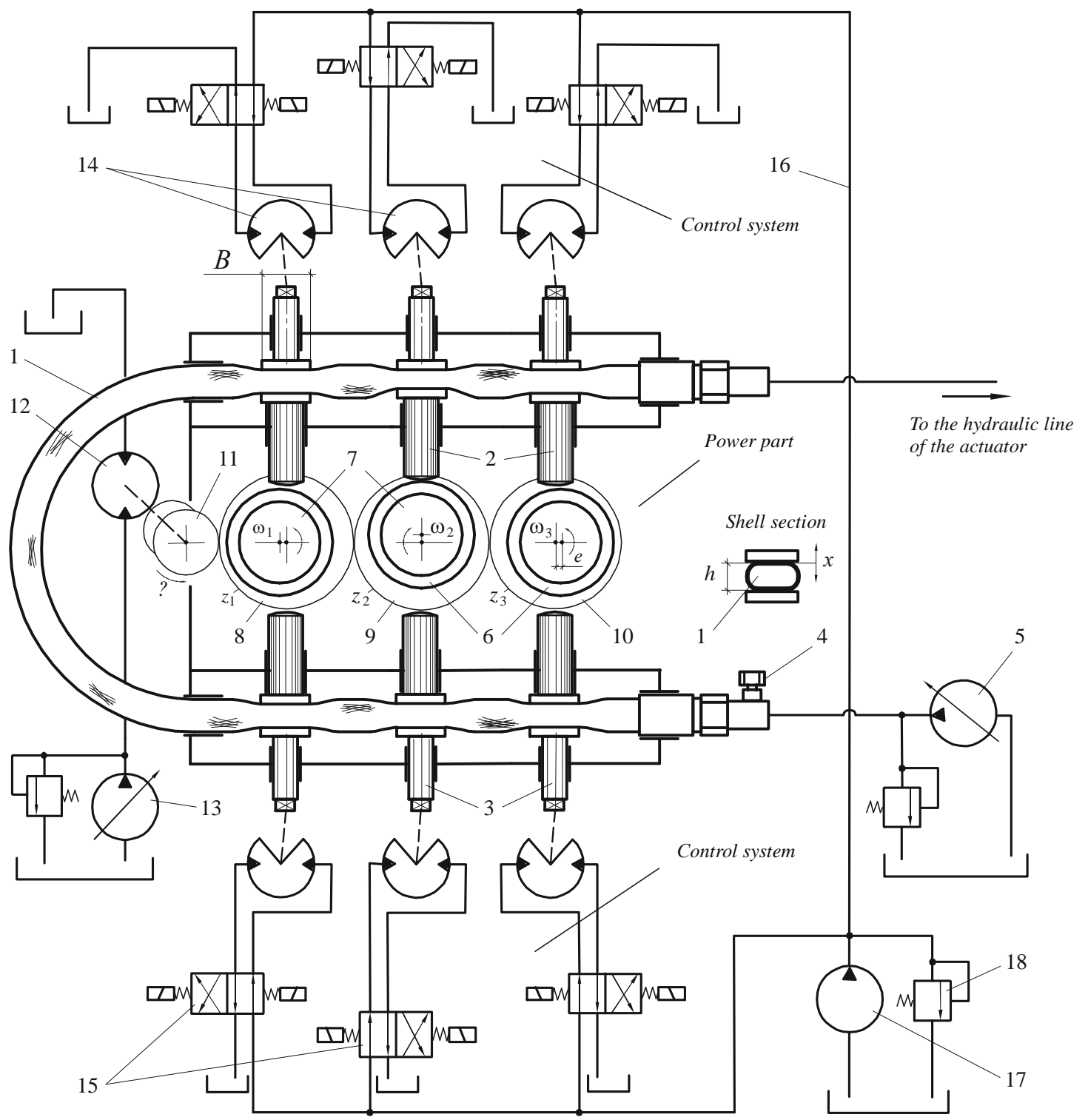

Fig.1. Hydromechanical diagram of the hydrostatic generator.

Gears 8, 9 and 10 are fixed on the eccentric shafts, which are in engaged with each other, while the ratio of the numbers of teeth of the gears 8 and 9 , as well as the ratio of the numbers of teeth 9 and 10 , are infinite non-periodic fractions, for example:

$$
\begin{aligned}
& \frac{z_{1}}{z_{2}}=\frac{47}{49} \approx 0.9592 \\
& \frac{z_{2}}{z_{3}}=\frac{49}{51} \approx 0.9608
\end{aligned}
$$


Obviously, the angular speeds of the gears will also be related

$$
\begin{aligned}
& \frac{\omega_{1}}{\omega_{2}}=\frac{47}{49} \approx 0.9592 \\
& \frac{\omega_{2}}{\omega_{3}}=\frac{49}{51} \approx 0.9608
\end{aligned}
$$

This is a key feature of the generator, since from the moment of its first start-up, such a relative position of the eccentrics, as shown in Fig. 1, will no longer be repeated, however, like any other of their relative position.

The drive of the eccentric gears is carried out through the drive gear 11, rotating at an angular speed $\omega$, connected to the gear 8 and the shaft of the hydraulic motor 12. The drive gear has a flywheel on its shaft, which eliminates the pulsation of the angular velocity of rotation. The hydraulic motor 12 through the gear system provides the reciprocating movement of the plungers and the operation of the generator. The hydraulic motor is driven by a variable pump 13 equipped with a safety valve. Hydraulic systems of the generator both in the power section and in the control system are shown in a simplified manner.

The shell in each pair of plunger-screw has a preliminary compression $h$. Preliminary compression can be changed by turning the screws 3 in the range $h_{\max } \ldots h_{\operatorname{mim}}$ using rotary hydraulic cylinders 14 . The rotary hydraulic cylinders 14 are controlled by on-off valves 15 . On-off valves 15 are controlled by generators of random signals (not shown in Fig. 1). The maximum duration of the signals $t$ income at the valve coils is due to by the time required for a complete rotation of the shaft of any of the hydraulic cylinders 14. But it can decrease randomly, like the very alternation of these signals. The operating fluid is supplied to the hydraulic line 16 from the unregulated pump 17 in such way that it is enough for the simultaneous operation of all rotary hydraulic cylinders for a time t. But such a coincidence when simultaneously all generators of random signals produce a signal with a maximum duration of $t$ is extremely unlikely. At any arbitrary period of time, the pump flow is excessive. Therefore, it is equipped with an overflow valve 18, which transfers excess operating fluid to the tank.

Due to the abovementioned minimum clearance between the ends of the plungers and the bearings of the eccentrics, the operating stroke of each plunger (up and down) and the displacement of the liquid from the shell correspond to the rotation of the eccentric by $165 \ldots 170^{\circ}$. Thus, if the preliminary compression of the shell $h$ on any of the plungers does not change and has a maximum value of $h_{\max }$, then the minimum volume of the operating fluid $w_{\text {mim }}$ displaced by it will be repeated with each revolution of the corresponding eccentric (Fig. 2). In this case, a pause takes place along the abscissa axis $\omega_{1} \cdot t$ (upper plunger). The operating stroke of the opposite (lower) plunger is performed antiphase and there is also a pause in this movement.

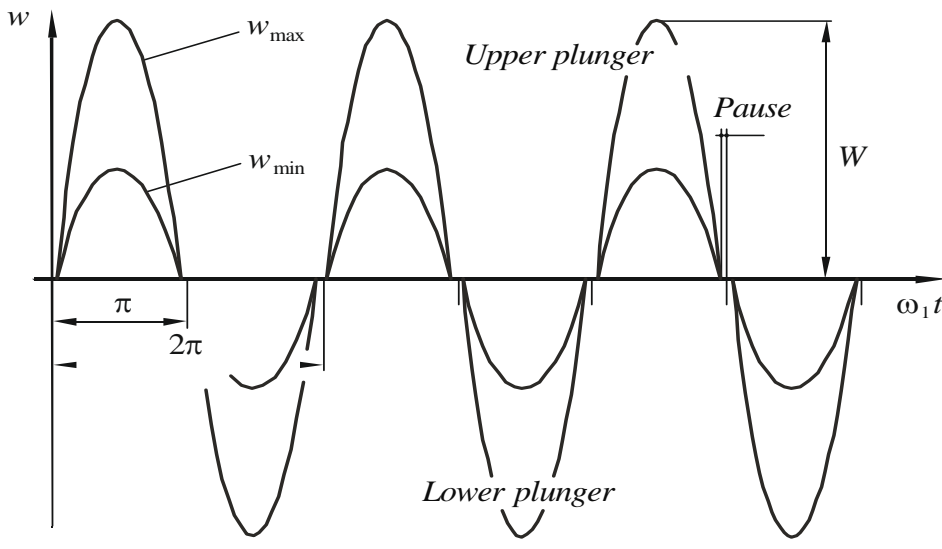

Fig. 2. Intervals between the volume impulses at different degrees of compression of the elastic shell

Thus, one period is equal to the time of one revolution of the eccentric and is a sum of four pauses $t_{\mathrm{p}}$ and the time $t_{\mathrm{d}}$ for displacing the volume $w$, which corresponds to one pressure impulse:

$$
T=t_{\mathrm{p}}+t_{\mathrm{d}}
$$


but it can vary over a wide range by changing the feed of the variable pump 13, and the angular speed of rotation of the driving generator gears 11 (Fig. 1). Let us consider another key element of the hydrostatic generator. It is the ability to regulate the volume of the operating fluid displaced from the shell $w$ by changing the upfront pressure build up $h$.

Let us introduce the concept of the kinematic characteristic of the elastic shell, which is the main power part of the generator of non-periodic impulses. The full volume of pump 5 (Fig.) 1 is passed through the elastic shell. The elastic shell together with the plungers, provide a non-periodic supply of volumes of operating fluid and make it possible to control their value. The kinematic characteristic is the dependence of the displaced volume $w$ on the relative radial deformation of the shell $x$ (see the shell section Fig. 1) without taking into account the effect of pressure.

The indicated dependence is quadratic, so omitting the intermediate formulas, we write:

$$
w=a_{1} x+a_{2} x^{2}
$$

where $a_{1}$ and $a_{2}$ are the coefficients of the kinematic characteristics that determine the range of regulation of the amplitude $W$ of the displaced volume (Fig. 2):

$$
\begin{aligned}
& a_{1}=\pi \cdot\left[\frac{B}{2}(d-h)+\frac{1}{4}(d-h)^{2}\right], \\
& a_{2}=0.25 \pi \cdot(B+d-h),
\end{aligned}
$$

where $B$ is the length of the compressed section of the shell, $d$ is its outer diameter, which does not change with the increasing of internal pressure, $h$ is the preliminary compression set by screws 3 (Fig. 1).

The limits of variation of the parameter $h$ have design constraints:

$$
\begin{aligned}
& h_{\max }=d-e, \\
& h_{\min }=d-0.5 d_{0}+e,
\end{aligned}
$$

where $d_{0}$ is the inner diameter of the shell.

Thus, the larger the standard size of the shell (high pressure hose), the wider the range of regulation of the amplitude $W$ of the displaced volume. In addition, when pressure increases, the inner diameter increases as well, and this expands the $h$ regulation range.

Moreover, only in the «neutral» (initial) state their phase positions will be equal:

$$
\varphi_{1}=\varphi_{3}=\varphi_{2}=0 \text {, }
$$

and with the beginning of rotation, the phase relations will change and during a very long time interval $t$ the ratio of the current values:

$$
\frac{\varphi_{1}(t)}{\varphi_{2}(t)}=\frac{\omega_{1}}{\omega_{2}} \approx 0.9592 ; \quad \frac{\varphi_{2}(t)}{\varphi_{3}(t)}=\frac{\omega_{2}}{\omega_{3}} \approx 0.9608
$$

remain infinite non-periodic fractions.

Obviously, time between pressure and volume impulses generated by the plungers are never exactly the same because the ratios of the angular velocities of the eccentrics are expressed in infinite periodic decimal fractions. Therefore, the total volume of liquid displaced by all plungers is a non-periodic (random) sequence of impulses. The estimated graph of the total liquid volume random time changes are shown in Figure 3 . The graph shows the possible behavior of the operational liquid displaced by the plungers at one period.

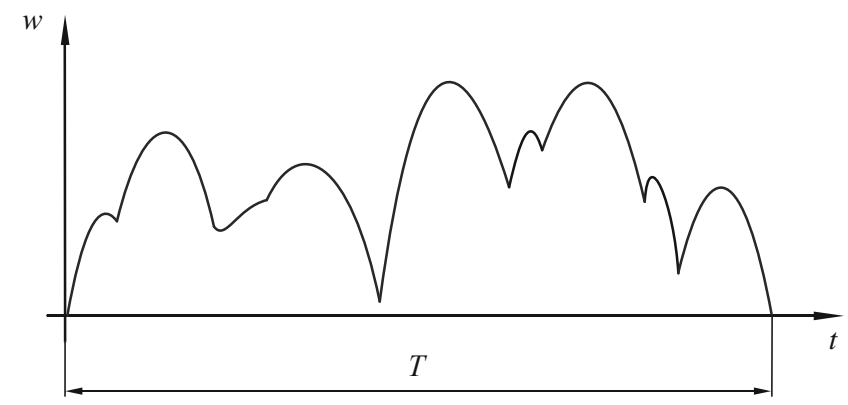

Fig. 3. Graph shows the frequency at which the volume of liquid displaced from the elastic shell of the generator of non-periodic pressure impulses 
The period corresponds to the full revolution of the eccentric which rotates with the angular velocity $\omega_{1}$. In the next period, the impulse sequence will be different. Harmonic analysis of such sequences gives a continuous spectrum of harmonics, which is constantly changing in the ratio of amplitudes and frequencies over time [20].

\section{The use of generator in testing machines.}

A large number of failures in mechanical engineering products are caused by vibration that occurs during the operation of their own power plants, from transport vibration and other reasons. At the same time, heavy dynamic loads can lead to functional disorder of hydromechanical, pneumatic, electrohydraulic and similar devices (vibrostability loss) as well as to mechanical breakage of structural elements of such devices (vibration strength loss). Before these products will be sent into mass production, they must be tested under extreme conditions [22-28].

There are several methods to test for vibration:

- the method of gradual increase of excitation frequency;

- the method of amplitude-modulated oscillations, etc.

The best effect is given by the tests carried out in a random vibration mode [19, 20], since any technical object and its elements vibrate at a spectrum of natural frequencies resonating to the continuous spectrum of the harmonics of the exciting impulses .

Figure 4 shows a simplified hydraulic diagram of a bench for technical products testing for vibrostability and vibration strength with a hydrostatic generator of non-periodic pressure impulses 1 . A hydraulic motor 2 and an adjustable pump 3 rotate its eccentrics.

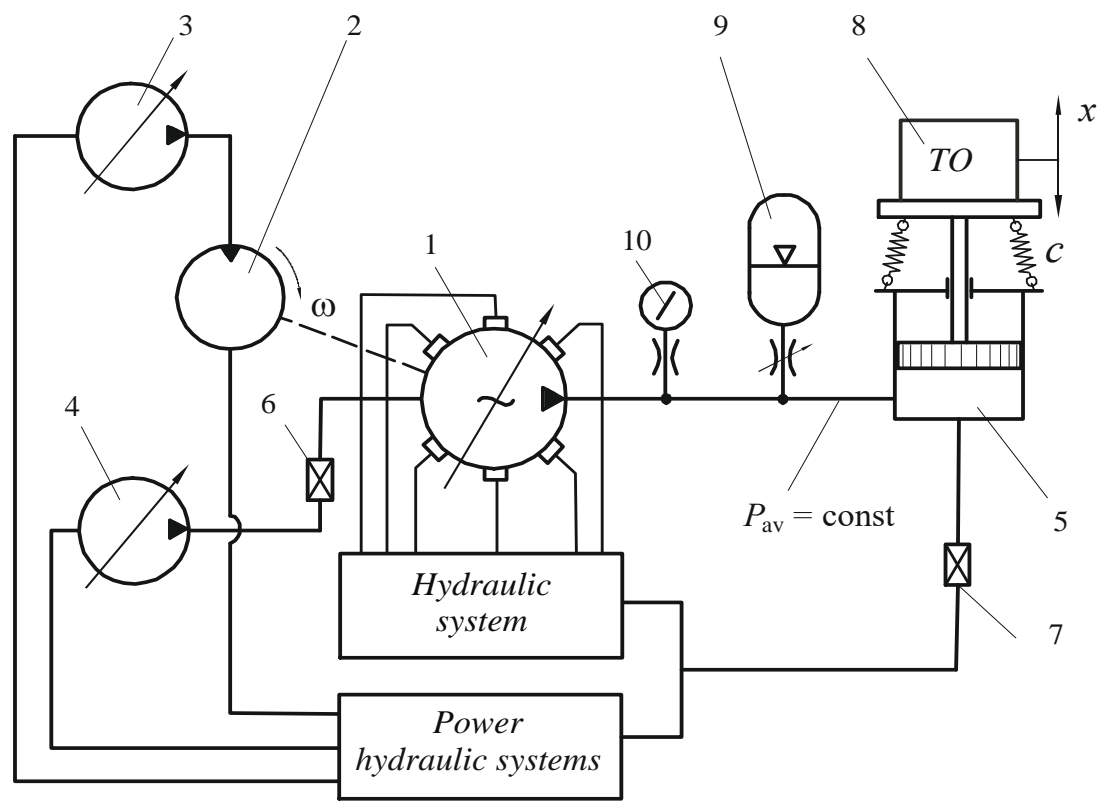

Fig.4. Hydraulic diagram of the bench for testing the technical objects

Pump 4 is designed to fill the generator, hydraulic lines connected with it and the actuator - hydraulic cylinder 5 . When a set initial pressure is reached, the pump is turned off, and the hydraulic lines are closed with sealed valves 6 and 7. After starting the generator, the pressure impulses enter the piston holes and cause random oscillations of the hydraulic cylinder table. The test object 8 (TO) is fixed on the hydraulic cylinder table. The hydraulic and pneumatic accumulator 9 maintains an average pressure, compensating for leaks of the operating fluid in the rod end of the hydraulic cylinder, and the pressure gauge 10 serves to control the average pressure $P_{\text {av }}$

To eliminate the influence of the impedance of the actuator moving part, its natural frequency should be beyond the frequency range covered, and the stiffness of the oscillatory system, determined mainly by the volumes of fluid contained in the both hydraulic cylinder holes:

$$
c=c_{\mathrm{sp}}+2 F_{2}^{2} \frac{E}{W_{0}},
$$


should be maximum $\left(c_{\mathrm{sp}}\right.$ is the total stiffness of the springs, $F$ is the area of the piston, $E$ is the elastic modulus of the fluid, $W_{0}$ is the volume of fluid in the holes of the hydraulic cylinder and adjacent lines).

The volume of the piston holes of the hydraulic cylinder and the volumes of the hydraulic lines should be minimized in design, and the natural frequency of oscillations of the hydraulic cylinder table $f_{0}$, taking into account the added mass of the test object, should exceed the upper limit of the frequency range $f_{\max }$ by at least an order of magnitude:

$$
f_{0}=\frac{1}{2 \pi} \sqrt{\left(\frac{1}{\left(m+m_{\mathrm{TO}}\right)}\right) \cdot\left(c_{\mathrm{sp}}+\frac{2 F_{2}^{2} E}{W_{0}}\right)}>10 f_{\text {max }},
$$

where $\mathrm{m}$ is the mass of the moving parts of the hydraulic cylinder, $m_{o u}$ is the mass of the test object.

Not only mechanical vibration can lead to failures of elements of hydraulic systems of machines and equipment, but also pressure pulsation that occurs when external loads are abruptly removed from the operating equipment of machines, when occurs hydraulic shocks of various origins, with the occurrence of resonant vibrations in hydraulic devices, etc. Hydraulic jump and non-periodic sequences of pressure impulses as mechanical factors can lead to dynamic loads. They can cause not only failure of normal functioning (vibrostability loss) and even mechanical failure of such elements (vibration strength loss).

A special bench based on a hydrostatic generator of non-periodic pressure impulse which is shown in Fig.5, can be used for testing hydraulic devices, hydraulic panels, hydraulic units, as well as high-pressure hoses when loaded with pulsating pressure.

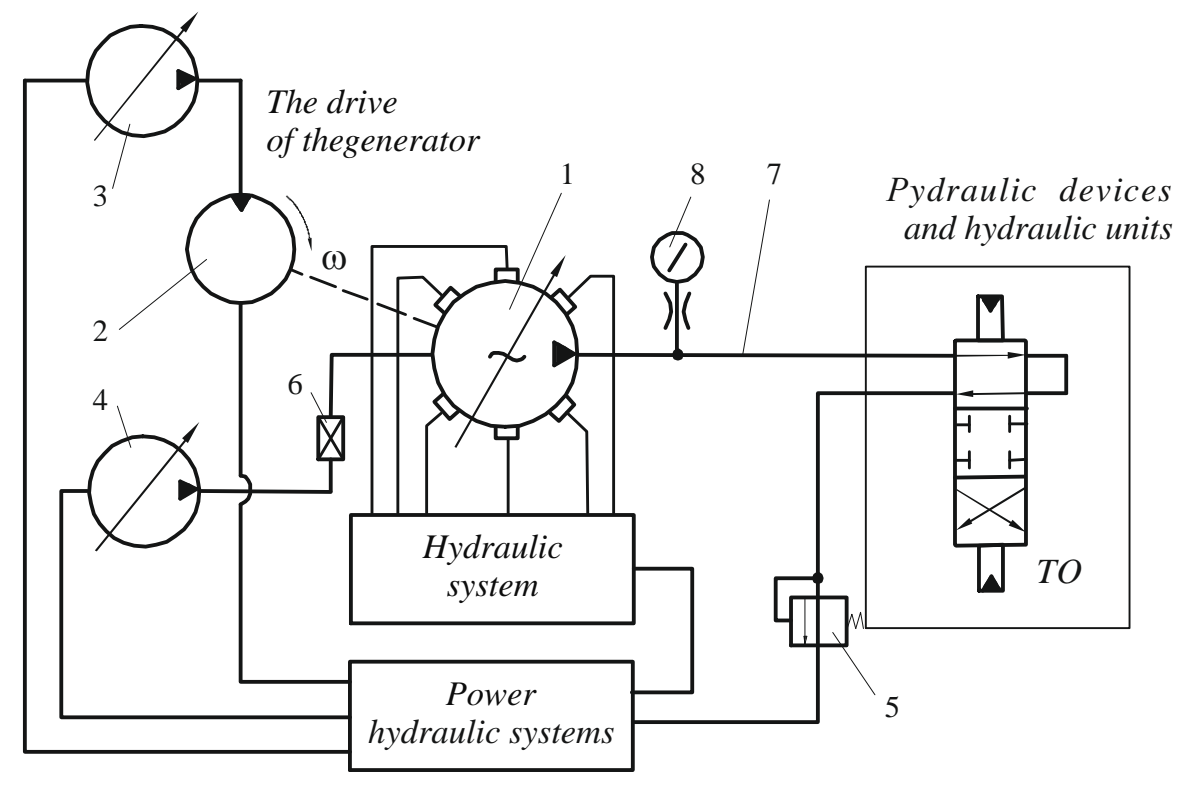

Fig.5. Hydraulic diagram of the bench for testing of the technical products by internal pressure.

Analogically to the described above test bench, the present one also operates with one main power unit that is also the hydrostatic generator 1 . The generator is connected to rotary hydraulic cylinders and electrohydraulic valves are included in the hydraulic control system. The hydraulic motor 2, which is connected to the pump 3, rotates the generator eccentrics. There is a pump 4 that fills the generator, hydraulic lines and the connected test object, but it also creates a flow of operating fluid under the operating pressure of the test object created by the back-up valve 5 . When valve 6 is opened, the flow of high pressure operating fluid is passed through line 7 to the technical product under test. The flow of operating fluid subjects it to a continuous sequence of non-periodic impulses. The impulses are formed during the operation of the generator. Pressure gauge 8 controls the pressure level.

During the tests, the constant operation must be provided for the hydraulic distributor, valve, hydraulic lock, or a set of elements of the hydraulic panel or valve body as an integral unit and the same ways as in normal conditions. In recent years, different equipment for submersible operation is developed and, in particular, unmanned submersible vehicles that perform many different tasks. It requires a large number of instruments and equipment - optical, lighting, speed and pressure sensors and many others, which must undergo a set of pressure tests $[3,29]$. 
There is a bench shown in Figure 6. That bench is design to put pressure on submersible equipment on the conditions of constant sequence of non-periodic impulses. It allows to carry out dynamic tests of the mentioned submersible devices and equipment for hermiticity, strength and stability of operating parameters under conditions of chaotically changing dynamic pressure of the environment.

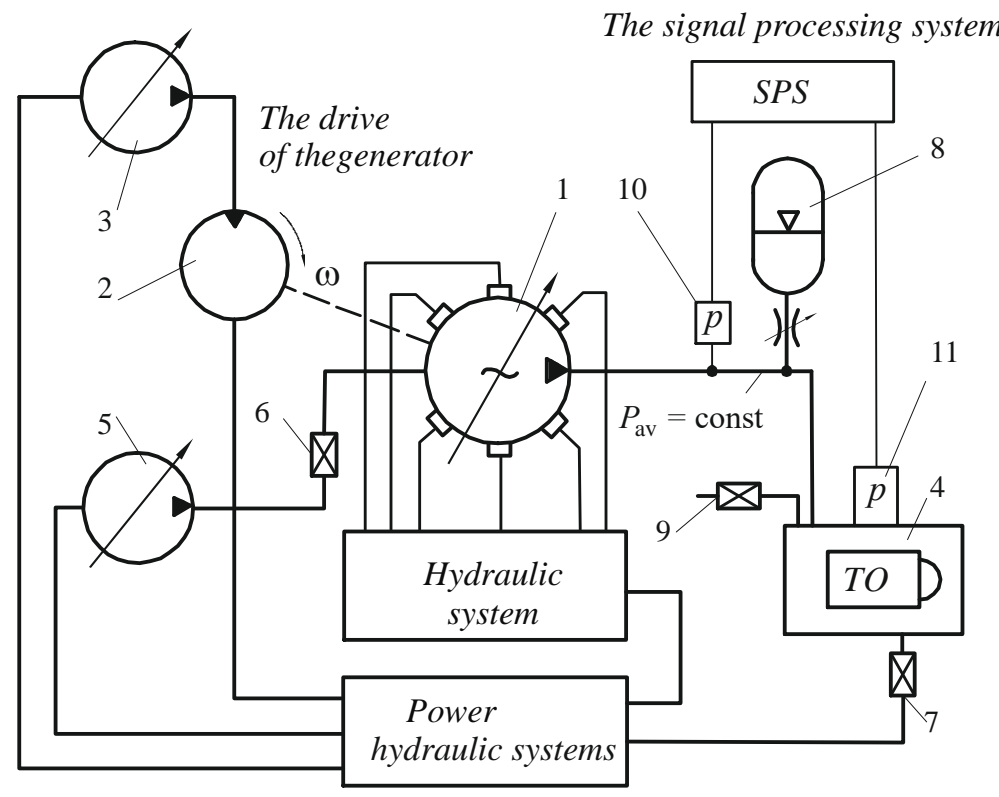

Fig.6. Hydraulic diagram of the test bench for testing technical devices by external pressure

When the eccentrics of the hydrostatic generator 1 is rotated by the hydraulic motor 2 and the pump 3 , then a continuous sequence of non-periodic pressure impulses is created in the test chamber 4 , where the TO test object is located, against the background of constant pressure created by the pump 5. Pump 5 pre-fills chamber 4, creating the required static pressure in it and turns off. Valves 6 and 7 provide seal the chamber, and the hydraulic and pneumatic accumulator 8 maintains a constantly maintains pressure at average value in the chamber, compensating for pressure leaks. Valve 9 is to release air when filling the test chamber. The signal processing system contains pressure sensors 10 and 11 . Since the angular velocities of the eccentrics are related as infinite periodic decimal fractions ( 3 and 4$)$, the phase angles of the eccentrics of the generator, figure 1 will never be equal.

The sequences of impulses generated by the plungers are added so that the total fluid volume which is compressed in the test chamber 4, figure 6 will change in the same way as shown in figure 3 . If we consider the fluid elasticity modulus $\mathrm{k}\left(\mathrm{N} / \mathrm{m}^{2}\right)$ to be free of pressure, then a gas free fluid [30] equation will look as follow

$$
k=w_{0} \frac{\Delta p}{w_{\Sigma}},
$$

where $w_{0}$ is the initial fluid volume in the test chamber at the initial average pressure $P_{\mathrm{av}}, \Delta p$ is the change in dynamic pressure relative to the initial one caused by the total fluid volume $w_{\Sigma}$ entering the test chamber.

It follows from the formula (11) that in order to achieve maximum pressure impulses, the initial volume $w_{0}$, as well as the volume of all hydraulic lines approaching the test chamber, should be minimal. According to the signal waveform alteration passing from the sensor 10 to the measuring and processing system of vibration signal with a constant signal waveform from the pressure sensor 11 it is possible to diagnose the test object. Also it is possible to diagnose them by using spectral analysis data.

\section{Conclusions}

In the result of our work we have created a new patented technical solution in the field of testing machines - a hydrostatic generator of non-periodic pressure impulses. While creating the hydrostatic generator of non-periodic pressure impulses, we also developed an alternative concept of hydrostatic generators to generate non-periodic pressure impulses and mechanical effects in the form of random 
vibration on various test objects, such as hydraulic and pneumatic devices, electronic and radio relay devices, on-board computers and other technical devices.

During the tests we have obtained the ratios of the angular velocities of the shafts, which provide the movement of the operating fluid into the actuator of the test bench in the form of a non-periodic function which impulses varying in amplitude in a random manner. It produces a continuous and non-repetitive sequence of pressure impulses and corresponds to the operation of the tested objects in real conditions. The random nature of the amplitudes settings is provided by the signals controlled from electric generators through controlled hydraulic valves. The random nature of the amplitudes settings is provided by signals controlled from electric generators through controlled hydraulic valves.

In addition, there were obtained the kinematic and dynamic dependencies for the developed hydromechanical systems using a new hydrostatic generator. The new hydrostatic generator is designed to test engineering objects for both mechanical random vibration and external and internal pressure tests of those objects that operate in such conditions. In our research and tests resulted the expansion of the range of systems and methods for the implementation of test processes under random non-periodic force effects on various engineering objects.

\section{REFERENCES}

1 Chelomej V.N. Vibrations in technology: a handbook in 6 volumes. Vol. 4. Vibration processes and machines. Moscow, Mashinostroenie, 1981, 509 p. [in Russian]

2 Gavrilin A.N., Moyzes B.B., Zharkevich O. Constructive and processing methods of reducing vibration level of the metal-working machinery elements. Journal of Vibroengineering. 2015, Vol. 17, No. 7, pp. 3496-3504.

3 Klyuev V.V. Test equipment: reference book. Moscow, Mashinostroenie, 1982, 560 p. [in Russian]

4 Surzhikov A.P., Frangulyan T.S., Ghyngazov S.A. A thermoanalysis of phase transformations and linear shrinkage kinetics of ceramics made from ultrafine plasmochemical $\mathrm{ZrO}_{2}(\mathrm{Y})-\mathrm{Al}_{2} \mathrm{O}_{3}$ powders. Journal of Thermal Analysis and Calorimetry. 2014, Vol. 115, No. 2, pp. 1439-1445. doi:10.1007/s10973-013-3455-y.

5 Surzhikov A.P., Pritulov A.M., Lysenko E.N., Sokolovskii A.N., Vlasov V.A., Vasendina E.A. Influence of solid-phase ferritization method on phase composition of lithium-zinc ferrites with various concentration of zinc. Journal of Thermal Analysis and Calorimetry. 2012, Vol. 109, No. 1, pp. 63-67. doi:10.1007/s10973-011-1366-3.

6 Adam S.A., Abdul Jalil N.A., Rezali K.A. Md., Ngb Y.G., Sound and Vibration Research Group. The effect of posture and vibration magnitude on the vertical vibration transmissibility of tractor suspension system. International Journal of Industrial Ergonomics SO. 2020, Article No. 103014. doi: https://doi.or2/10.1016/3.ergon.2020.103014.

7 Adams M. Rotating Machinery Vibration: From Analysis to Troubleshooting. Boca Raton, 2009, 476 p.

8 Halit E. Acceleration, Vibration, and Shock Measurement. Abingdon, CRC Press LLC, 1999, 33 p.

9 Goinaraghi F., Kuo B. Automatic Control Systems. New York City, McGraw-Hill Education, 2017, 1160 p.

10 Steinwolf A. Random Vibration Testing beyond PSD Limitations. Sound\&vibration, 2006, Vol. 40, pp. 1221.

11 Nizhegorodov A.I., Gavrilin A.N., Moyzes B.B. Hydraulic power of vibration test stand with vibration generator based on switching device. Key Engineering Materials. 2015, Vol. 685, pp. 320-325.

12 Ahirrao N.S., Bhosle S.P., Nehete D.V. Dynamics and Vibration Measurements in Engines. Procedia Manufacturing, 2018, Vol. 20, pp. 434-439. doi: 10.1016/j.promfg.2018.02.063.

13 Czichos H. Handbook of Technical Diagnostics. Fundamentals and Application to Structures and Systems. Berlin, Springer Verlag Berlin Heidelberg, 565 p.

14 Ahirrao, N.S., Bhosle, S.P., Nehete, D.V. Dynamics and Vibration Measurements in Engines. Procedia Manufacturing. 2018, Vol. 20, pp. 434-439. doi: 10.1016/j.promfg.2018.02.063.

15 Forental, V.I., Forental, M.V., Nazarov, F.M. Investigation of dynamic characteristics of the hydraulic drive with proportional control. Procedia Engineering. 2015, Vol. 129, pp. 695-701. doi: 10.1016/j.proeng.2015.12.093.

16 Li L., Huang H., Zhao F., Liu Z. Operation scheduling of multi-hydraulic press system for energy consumption reduction. Journal of Cleaner Production. 2017, Vol. 165, pp. 1407-1419. doi: 10.1016/j.jclepro.2017.07.158.

17 Seimert, M., Gühmann, C. Vibration based diagnostic of cracks in hybrid ball bearings. Measurement: Journal of the Intern.Measurement Confederation. 2017, Vol. 108, pp. 201-206. doi: 10.1016/j.measurement.2017.03.001

18 Harris, C., Piersol, A. Harris' Shock and Vibration Handbook. (New York: McGraw-Hill Professional).

19 Guoqing Jiang, Yu Wang, Fengming Li, Xingjian Jing. An integrated nonlinear passive vibration control system and its vibration reduction properties. Journal of Sound and Vibration. 2021, Vol. 509, Article 116231.

20 Tyablikov Yu.E., Karamyshkin V.V., Frolov K.V. Features of the interaction of an oscillatory system of a given structure with an energy source. Elastic and hydroelastic vibrations of machine elements and structures. 1979, pp. 15-21. [in Russian] 
21 Krasilnikov A.V. Assembly and testing of units and systems of robotic marine technical equipment. SaintPetersburg, Saint-Petersburg institute of precision mechanics and Optics, 2013, 152 p. [in Russian]

22 Wang J., Qin H., Chen Y. Energy performance evaluation of an innovative hydrostatic motor. Renewable Energy. 2013, Vol. 57, pp. 197-505. doi:10.1016/j.renene.2013.01.059.

23 Schulte H., Gerland P. Observer-based estimation of pressure signals in hydrostatic transmissions. IFAC Proceedings. 2010, Vol. 43, No. 7, pp. 425-430. doi:10.3182/20100712-3-DE-2013.00053.

24 Delmas H., Ngoc Tuan Le, Barthe L., Julcour-Lebigue C. Optimization of hydrostatic pressure at varied sonication conditions - power density, intensity, very low frequency - for isothermal ultrasonic sludge treatment. Ultrasonics Sonochemistry, 2015, Vol. 25, pp. 51-59. doi:10.1016/j.ultsonch.2014.08.011.

25 Shamshirband S., Dalibor Petkovic D., Amini A. et al. Support vector regression methodology for wind turbine reaction torque prediction with power-split hydrostatic continuous variable transmission. Energy, 2017, Vol. 67, pp. 623-630. doi:10.1016/j.energy.2014.01.111.

26 Nizhegorodov, A.I., Gavrilin, A.N., Moyzes, B.B., Cherkasov, A.I., Zharkevich, O.M., Zhetessova, G.S., Savelyeva, N.A. Radial-piston pump for drive of test machines. IOP Conference Series: Materials Science and Engineering. 2018, Vol. 289, No. 1, art. no. 012014. doi: 10.1088/1757-899X/289/1/012014.

27 Gavrilin, A.N., Chuprin, E.A., Moyzes, B.B., Halabuzar, E.A. Land-based sources of seismic signals. Proceedings of 2014 International Conference on Mechanical Engineering, Automation and Control Systems, MEACS 2014, 2014, art. no. 6986947. doi: 10.1109/MEACS.2014.6986947.

28 Youhong Sun, Yuanling Shi, Qingyan Wang, A Ei, Zongwei Yao. Study on speed characteristics of hydraulic top drive under fluctuating load. Journal of Petroleum Science and Engineering. 2018, Vol. 167, pp. $277-286$.

29 Pavlov A.I., Polyanin I.A., Kozlov K.E. Improving the Reliability of Hydraulic Drives Components. Procedia Engineering, 2017, Vol. 206, pp. 1629-1635. doi:10.1016/j.proeng.2017.10.689.

Russian]

30 Prokofiev V.N. Mechanical engineering hydraulic drive. Moscow, Mashinostroenie, 1978, 495 p. [in 